\title{
PLASTIC DEFORMATION ZONE IN ELECTROMAGNETIC CUTTING
}

\begin{abstract}
This paper presents the application of the electromagnetic field as a tool for metal sheet cutting. The experiments showed that one can easily adapt the conventional cutting equipment to the electromagnetic cutting technology and thereby eliminate the mechanical work of the punch and the press. Two methods exploiting the electromagnetic field as the tool for cutting sheet metal were used. In one of the methods the cutting element was a die while in the other method a punch was used for cutting. Owing to the high quality surface of the cut obtained by each of the methods the cutting process does not entail additional costs for removing burrs. The shape of the surface of the cut is different than the one obtained by traditional blanking - no zones characteristic of the latter are present here. In the case of both materials, the rollover of the sheet surface is much larger and longer than in the conventional method. In comparison with the conventional method, the electromagnetic machining technology ensures high quality of the surface of the cut and can be successfully used in the industry.

Keywords: metal forming, electromagnetic sheet metal cutting, aluminium, copper
\end{abstract}

\section{Introduction}

In recent years as it became necessary to reduce the weight of motor vehicles the use of light metal alloys in their manufacture has increased. In the conditions of limited natural resources, increasing natural environment pollution, the necessity of saving energy and the consequent stringent legal requirements (recycling), light construction materials become increasingly important. Moreover, companies introduce state-of-the-art technologies to further enhance their products, which in turn leads to even more innovative solutions [1,2]. For this reason in the highly innovative automotive industry light construction material are used on an increasingly large scale.

Light constructions made of aluminium and magnesium alloys are used in the drive unit, the body, the chassis and other car components. Thus there is a great potential for the use of such alloys for car bodies [3]. Aluminium (having a density of $2.7 \mathrm{~g} / \mathrm{cm}^{3}$ ) follows steel (having a density of $7.8 \mathrm{~g} / \mathrm{cm}^{3}$ ) as the metal most commonly used in the car industry.

One of the modern methods of plastic forming aluminium alloys is electromagnetic forming [4]. This method is most often used in practice to form metal sheets at high deformation rates. The action of electromagnetic field forces can be exploited to join, form, extrude, weld and cut sheet metal [5]. In these processes, mainly materials with high electric conductance, such as aluminium or copper alloys, are used. This technology (created in 1960) has been the subject of numerous studies and has been intensively developed in the last decade.
As opposed to the conventional ways of plastic forming metals by means of punches, rolls and press-forming dies, electromagnetic forming exploits contactlessly acting Lorenz forces. The energy of a strong magnetic field makes the material deform at a high rate. The energy needed for this purpose is stored in a bank of capacitors. At the start of the process, the capacitors are charged with electric energy and then the latter is converted into mechanical energy [6]. Thanks to this technology much larger limit deformations than in conventional forming methods are achieved. At high strain rates the loss of stability by sheet metal is delayed, whereby its formability significantly increases and springback is eliminated [7]. As a result, a higher drawpiece dimensional accuracy is achieved.

The electromagnetic field can also be used as a tool for cutting. Newer developments of electromagnetic cutting are presented by Kautz [8]. This technology offers time and energy savings. For example, it can be used to blank holes for electric cables in car body sheets [9]. Another possibility is to use lasers for cutting, but this requires high power whereby the process is time-consuming and costly. It takes about $1.4 \mathrm{~s}$ to cut a hole by means of a laser whereas an electromagnetic pulse can do this job in about 200 milliseconds. The electromagnetic machining method is up to seven times faster. Its another advantage is that it causes no significant burring whereby no additional finishing operations are needed $[10,11]$. In contrast, the use of the conventional cutting technology results in undesirable burrs, which entails additional work and time $[12,13]$.

\footnotetext{
* WROCŁAW UNIVERSITY OF TECHNOLOGY, DEPARTMENT OF METAL FORMING AND METROLOGY, WYBRZEŻE WYSPIAŃSKIEGO 25, 50-370 WROCŁAW, POLAND

Corresponding author: zbigniew.zimniak@pwr.edu.pl
} 
Recent work [14-18] has demonstrated the ability to metalcutting by combining electromagnetic and mechanical forces. The magnetic saw effect, induced by the Lorentz force generated due to the application of a series of electromagnetic (EM) pulses, can be utilized to cut a metallic component containing a pre-existing cut or crack. A novel tool-less, free-formed manufacturing process, is particularly suitable for hard-to-cut metals.

An industrial application of an electromagnetically cut component - a crashbox is presented in Schäfer and Pasquale [19]. Here, it is emphasized that electromagnetic compression is applied for forming and cutting in one and the same pulse. In Kräusel et al. [20] it is mentioned that even the cutting of high strength steel $22 \mathrm{MnB} 5$ is possible.

The equipment for electromagnetic cutting does not include a one cutting tool subject to wear, which results in lower electric energy consumption and costs. In contrast, in the course of conventional cutting the cutting tools wear out, which has an adverse effect on the dimensional accuracy and appearance of the workpiece.

This paper presents two methods exploiting the electromagnetic field as a tool for cutting sheet metal. In one of the methods a conventional cutting tool (a die) is used, but the equipment also includes a high voltage supply unit, a bank of capacitors, a trip circuit and a special coil which generates an electromagnetic field. In the other method, an electromagnetic head and a punch (as a cutting element) are used for blanking.

It is demonstrated that one can easily adapt the available conventional devices to the electromagnetic cutting technology and in this way eliminate the mechanical action of the punch and the press. The electromagnetic machining technology ensures high cutting surface quality, saves time and reduces energy consumption. Owing to the high quality surface of the cut obtained by electromagnetic cutting process does not entail additional costs for removing burrs.

\section{Methodology of experimental investigation}

Experiments were carried using a specially designed setup for the electromagnetic cutting of metal sheets. It consisted of a high voltage power supply unit (Fig. 1a) with a maximum voltage of $3.0 \mathrm{kV}$, a bank of capacitors (Fig. 1b), feeder cables, a trip circuit and a working head. Thanks to the use of many capacitors, instead of a single capacitor with the same inductance, the total inductance of the bank is proportionally lower, whereby the pulse rise time is very short, ensuring a higher rate of material deformation. The setup energy used in the experiments amounted to $1.8 \mathrm{~kJ}$.

A specially designed bank of very fast RBPS pulse capacitors, six conventional capacitors with a total capacity of $400 \mu \mathrm{F}$ and a specially designed discharge switch (constituting the main current circuit) were connected to the power supply unit. The capacitor bank ensured a very short pulse rise time whereby the rate of deformation of the machined material was significantly higher.

The discharge switch (Fig. 2) is an in-house design created after many trials with various electrodes. Its electrodes have the form of coaxial cylinders mounted in a plastic insulator. This design ensures long lasting operation of the system without the wear out of the discharge electrodes.

The inner electrode constitutes a positive $(+)$ pole while the outer electrode is a negative (-) pole. Current is triggered by a trigger electrode. A discharge between the electrodes moves towards the trigger circuit's open space. The electrodes heat up less thanks to the large active surface and the shifting of the discharge.

The setup includes a measuring system enabling the recording of the principal process parameters. The measuring system comprises a laptop, an oscilloscope and a Rogowski coil for measuring the discharge current of the capacitors. The system enables the continuous change and recording of electromagnetic cutting process parameters.

Fig. 3 shows a typical trace of electric voltage over time, displayed on the screen of the digital oscilloscope.

The working head used in the experiments for first method is shown in Fig. 4.

The head, built by winding five turns of a square copper section ( $49 \mathrm{~mm}^{2}$ in cross section) on a plastic frame, generates a uniformly distributed electromagnetic field.
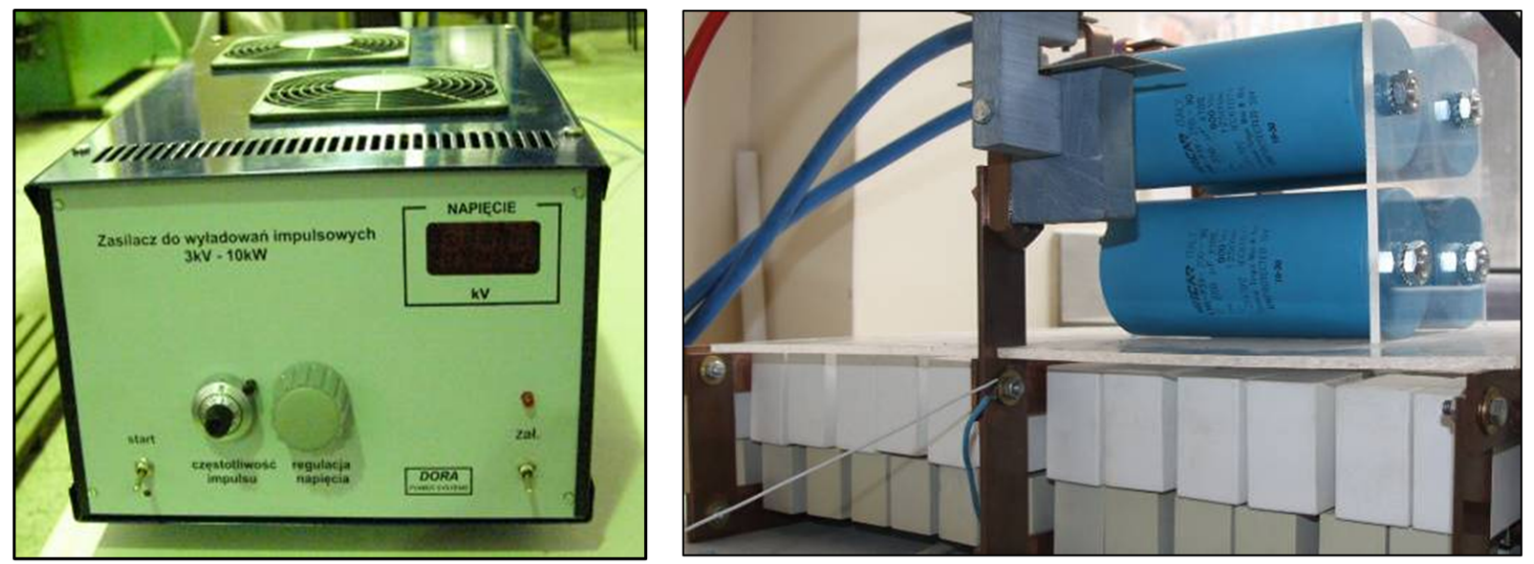

Fig. 1. Components of setup for electromagnetic cutting 

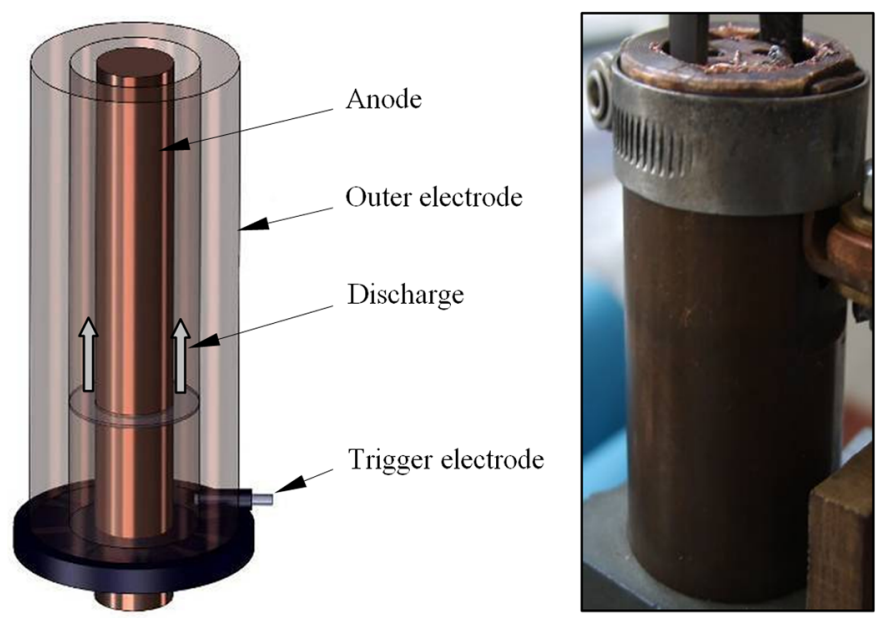

Fig. 2. Discharge switch design

Experiments for the first method were carried out using a conventional blanking tool with an additional electromagnetic head (Fig. 5).

In the second method, an electromagnetic head and a punch (as the cutting element $14 \mathrm{~mm}$ diameter) were used for cutting.

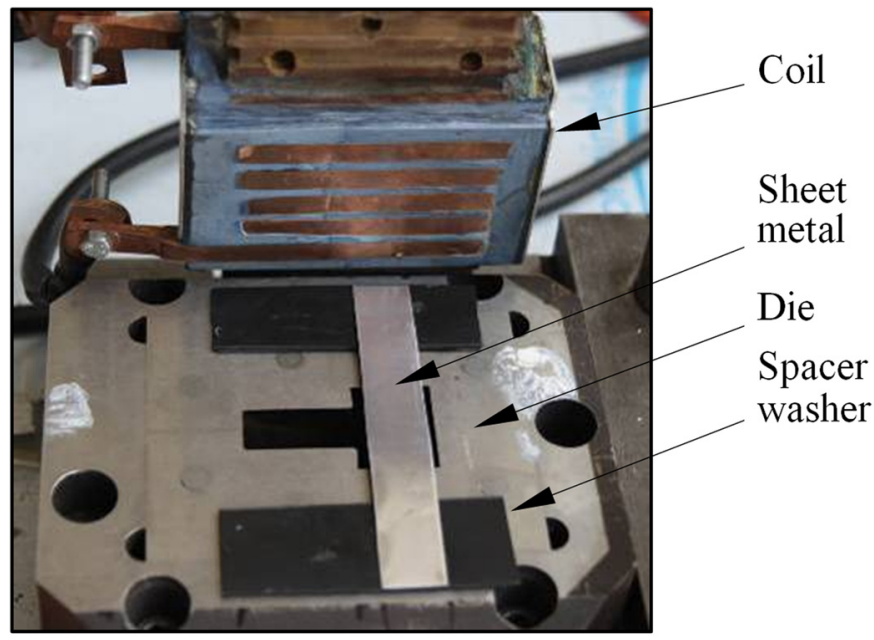

Fig. 4. View of conventional blanking tool with electromagnetic head

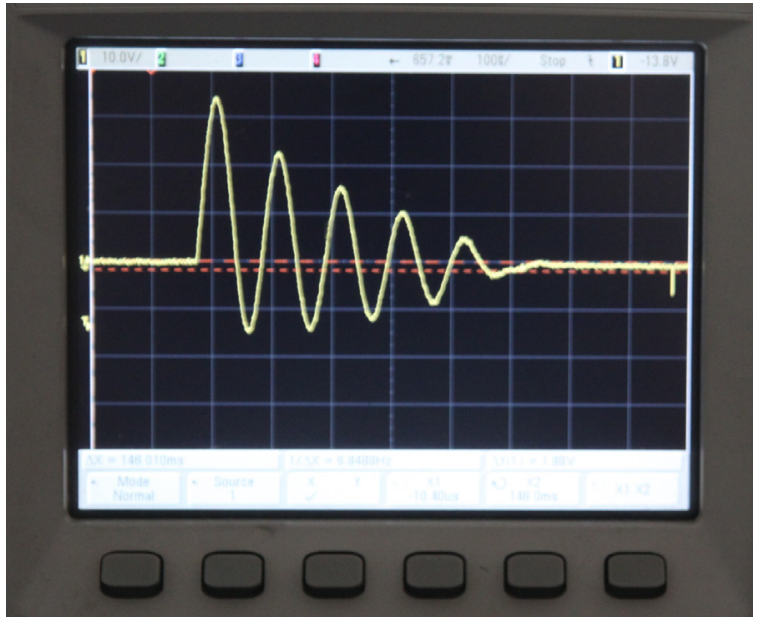

Fig. 3. Trace of voltage over time

The punch used for blanking holes was made of sintered carbide attached to a plastic plate (Fig. 6).

Plastic plate was pressed with force $F=200 \mathrm{~N}$.

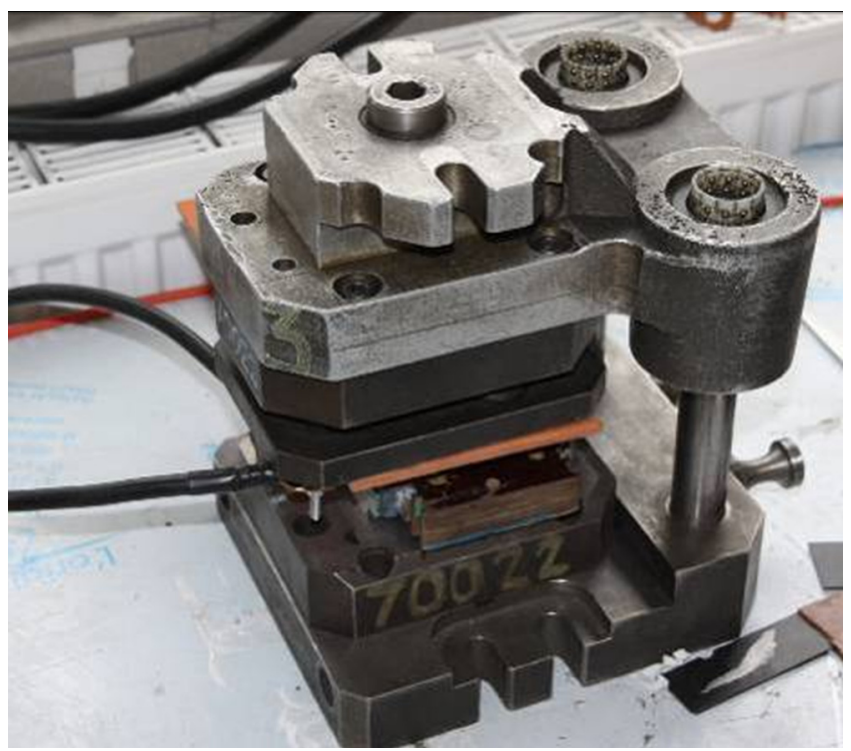

Fig. 5. Blanking tool with additional electromagnetic head

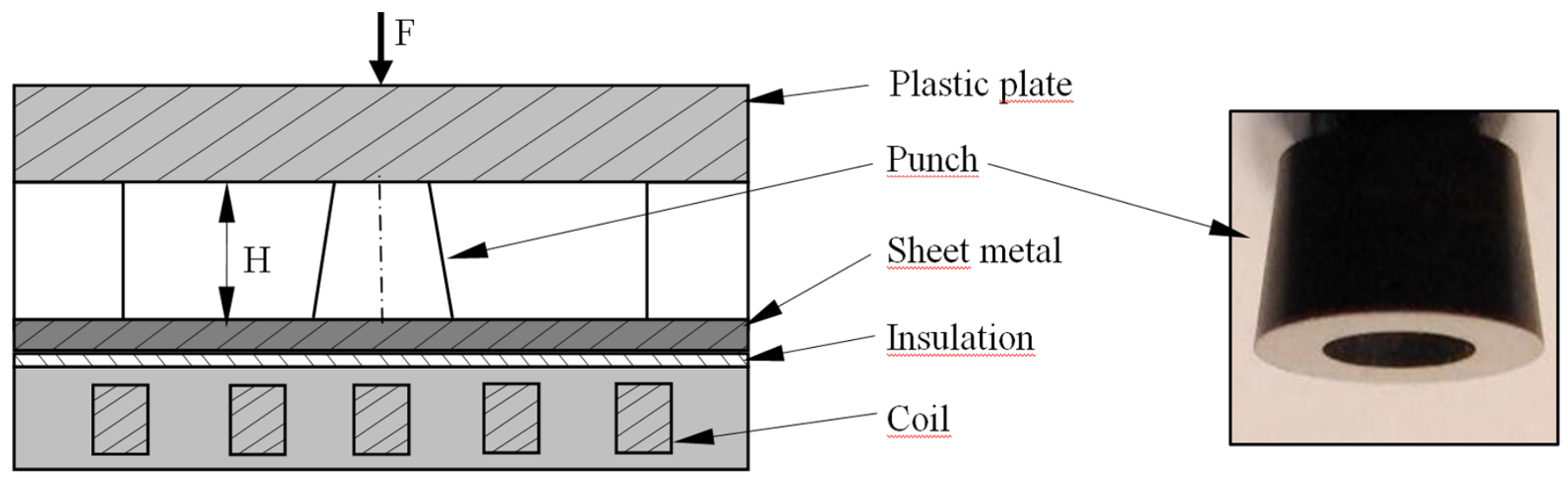

Fig. 6. Experimental setup and view of blanking punch 


\section{Results}

\subsection{Sheet metal cutting off by means of conventional blanking tool}

A working head generating a uniformly distributed electromagnetic field (Fig. 4) was used in the sheet metal cutting off experiments. The process consisted in the electromagnetic cutting of sheet metal by means of a die as the cutting element. The capacitor charging voltage was $2.5 \mathrm{kV}$, which resulted in an energy of $1.25 \mathrm{~kJ}$. Specimens in the form of $0.12 \mathrm{~mm}$ thick rectangular 60'140 mm sheet metal strips were used. Grade $1050 \mathrm{AH} 24$ aluminium was used as the specimen material. In the course of the experiments the distance of the sheet metal from the die was changed by means of spacer washers. This distance was one of the parameters critical for the success of the cutting process. Another critical parameter was the distance between the ends of the spacer washers and the cutting edges of the die.

The best cutting off results were achieved for the spacer washer thickness of $2.1 \mathrm{~mm}$. The distance between the two parallel cutting edges during the cutting amounted to $26.4 \mathrm{~mm}$. Fig. 7 shows a successful attempt at electromagnetic cutting off after the optimum process parameters had been determined.

The SEM picture in Fig. 8 shows the edge of the sheet metal after cutting off. The rollover of the sheet metal surface, observed in the initial elastoplastic stage of cutting, is much larger than in the case of the conventional method. The advantage of this kind of machining is a very high quality of the cut surface, which has no burrs.

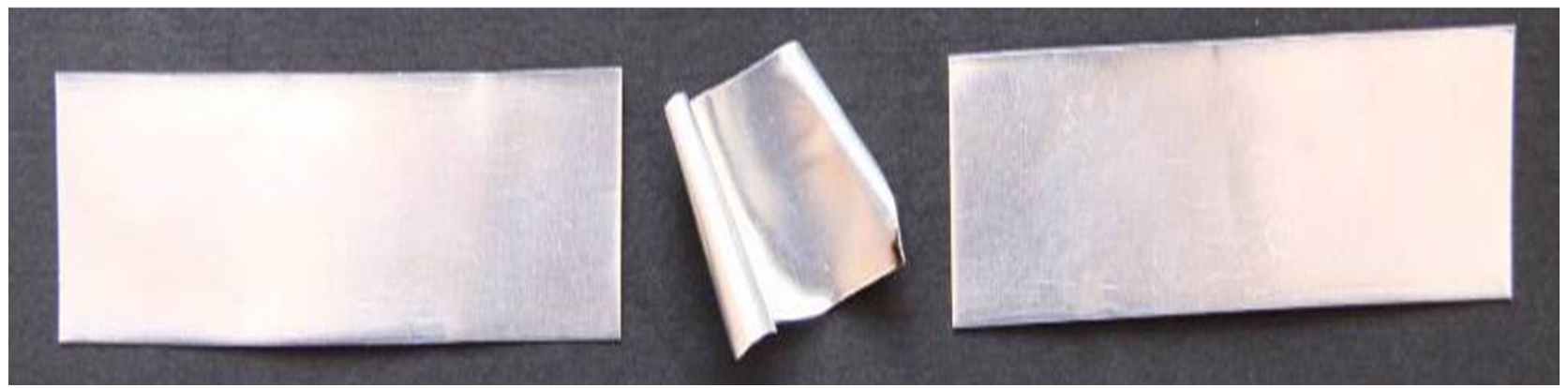

Fig. 7. Aluminium specimen after cutting off

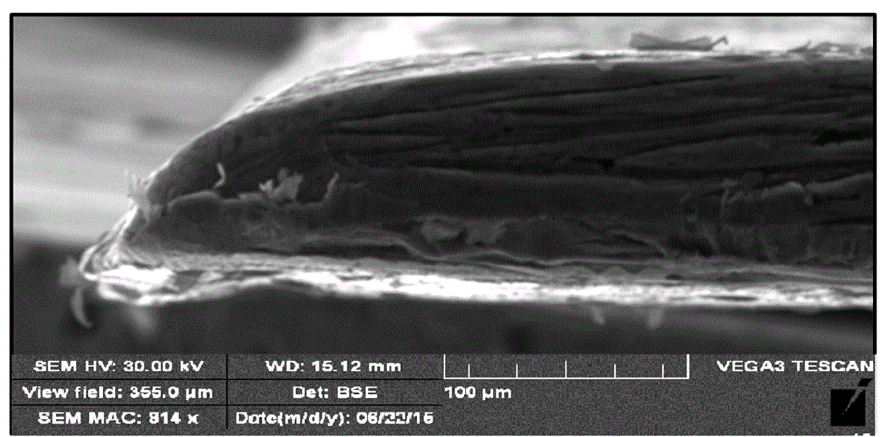

Fig. 8. Surface of specimen

\subsection{Sheet metal blanking using punch as cutting element}

In this method an electromagnetic head and a punch were used for cutting. The punch was made of sintered carbide and it was used as a cutting element for blanking. Blanking consisted in placing a metal sheet on the insulated head and applying the punch to it with a proper pressing force. On the application of an electromagnetic pulse the specimen would deform and be cut. The experiments were carried out on aluminium sheets and copper sheets. Specimens in the form of rectangular $30 \times 140 \mathrm{~mm}$ sheet metal strips were used. As the specimen materials $0.6 \mathrm{~mm}$ thick aluminium $1050 \mathrm{AH} 24$ and $0.3 \mathrm{~mm}$ thick copper M1E were used.
Different supply voltages, i.e. $2.2 \mathrm{kV}, 2.45 \mathrm{kV}$ and $2.8 \mathrm{kV}$, were used in the experiments. Also the effect of the applied energy and of the length of the punch on the effectiveness of blanking was studied. The applied energy was in a range of $0.97 \mathrm{~kJ}$ to $1.57 \mathrm{~kJ}$.

First the effect of punch length on the blanking process was studied. It was found that the process could not be effectively executed when the length of the punch was too small. Fig. 9
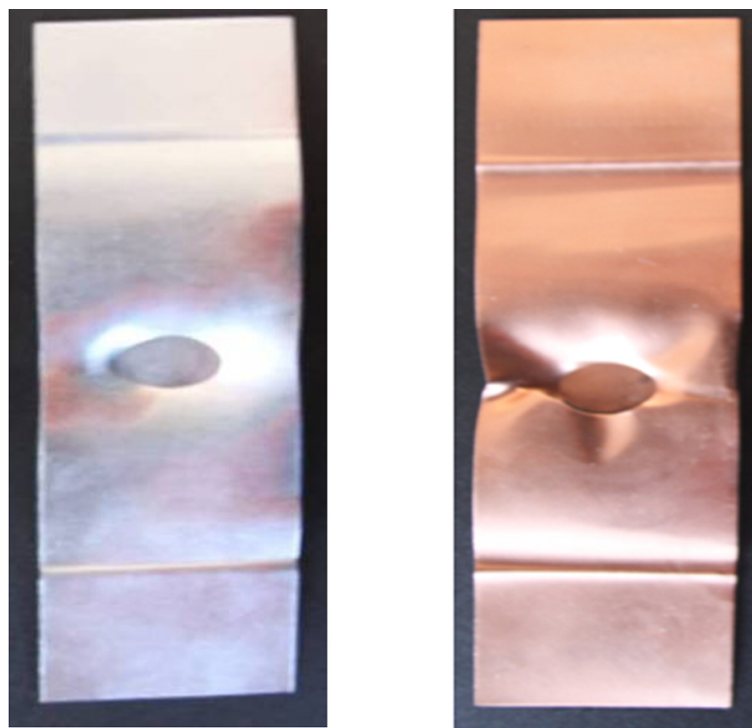

Fig. 9. Results of blanking trials for too short punch length 
shows the test results for the maximum energy of $1.57 \mathrm{~kJ}$ and a too small punch length $\mathrm{H}$ of $4 \mathrm{~mm}$. The attempt at cutting was unsuccessful for both the aluminium and copper sheet. Besides, the sheet being cut would fold too much. The optimum tool length ensuring that the material would be cut through amounted to $5.5 \mathrm{~mm}$.

Fig. 10 shows the test results for the two materials and different energy values at the optimum tool length. The application of the energy of $0.97 \mathrm{~kJ}$ did not result in the blanking of the aluminium sheet or the copper sheet. When the energy was increased to $1.20 \mathrm{~kJ}$, blanked were in both the materials. A further increase in the energy to $1.57 \mathrm{~kJ}$ resulted in much better quality of the product owing to the absence of sheet folding. The product quality was higher for the aluminium sheet, which was thicker than the copper sheet.

The quality of the blanking surfaces was evaluated under SEM. Fig. 11 shows the surface of the cut for respectively the aluminium sheet and the copper sheet. The shape of the surface is different than the one obtained by traditional blanking - no zones characteristic of the latter are present here.

In the case of both materials, the rollover of the sheet surface is much larger and longer than in the conventional method. The product's cut surface is of very high quality and completely devoid of burrs. For the aluminium sheet a rupture zone contiguous with the tool occurred. Such a zone did not occur in the case of the copper sheet.

\section{Conclusions}

Two methods exploiting the electromagnetic field as a tool for cutting sheet metal have been presented. In the first method, a die was the cutting element while in the second method a punch was used for this purpose. The following conclusions were drawn
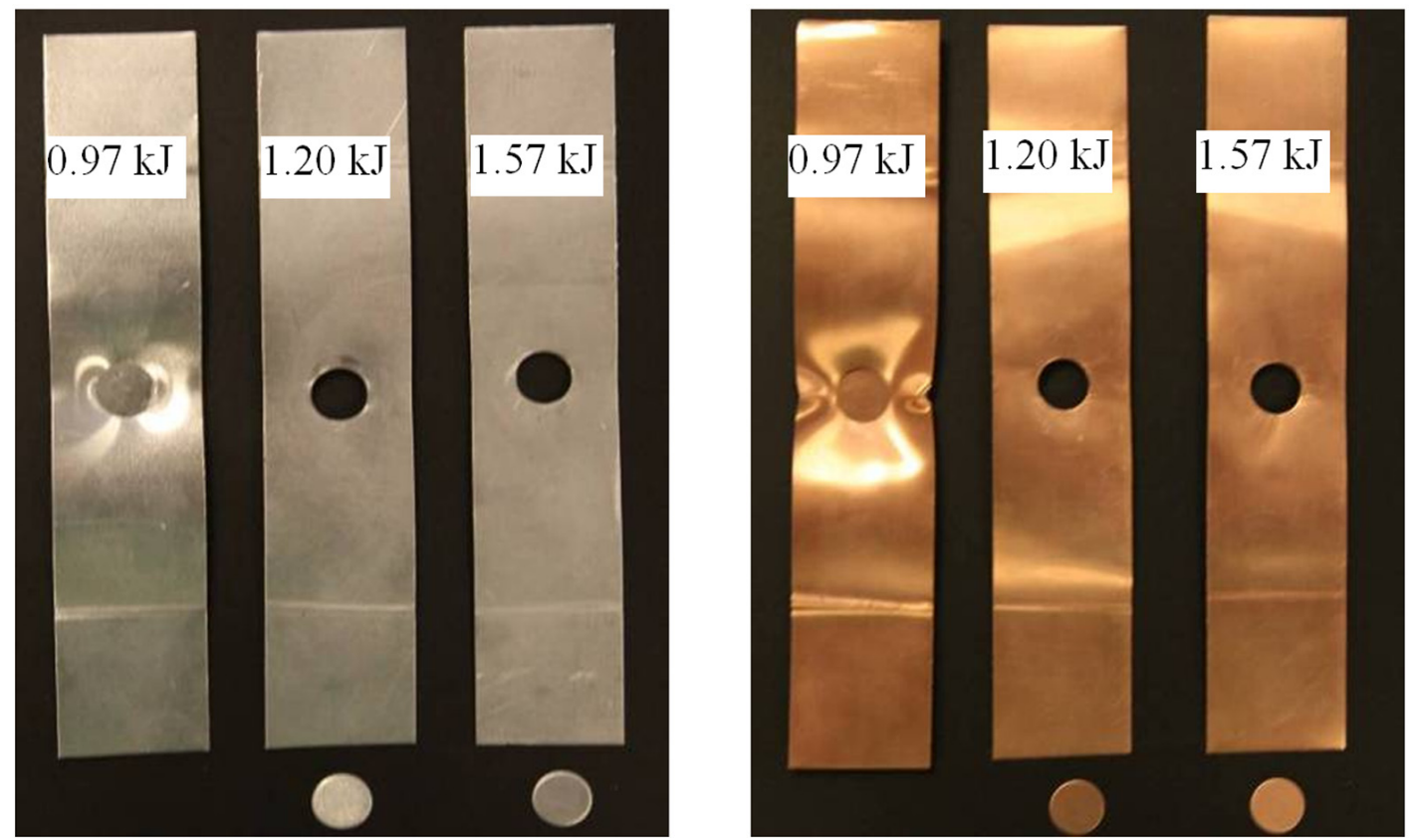

Fig. 10. View of sheets after electromagnetic blanking for different energy values
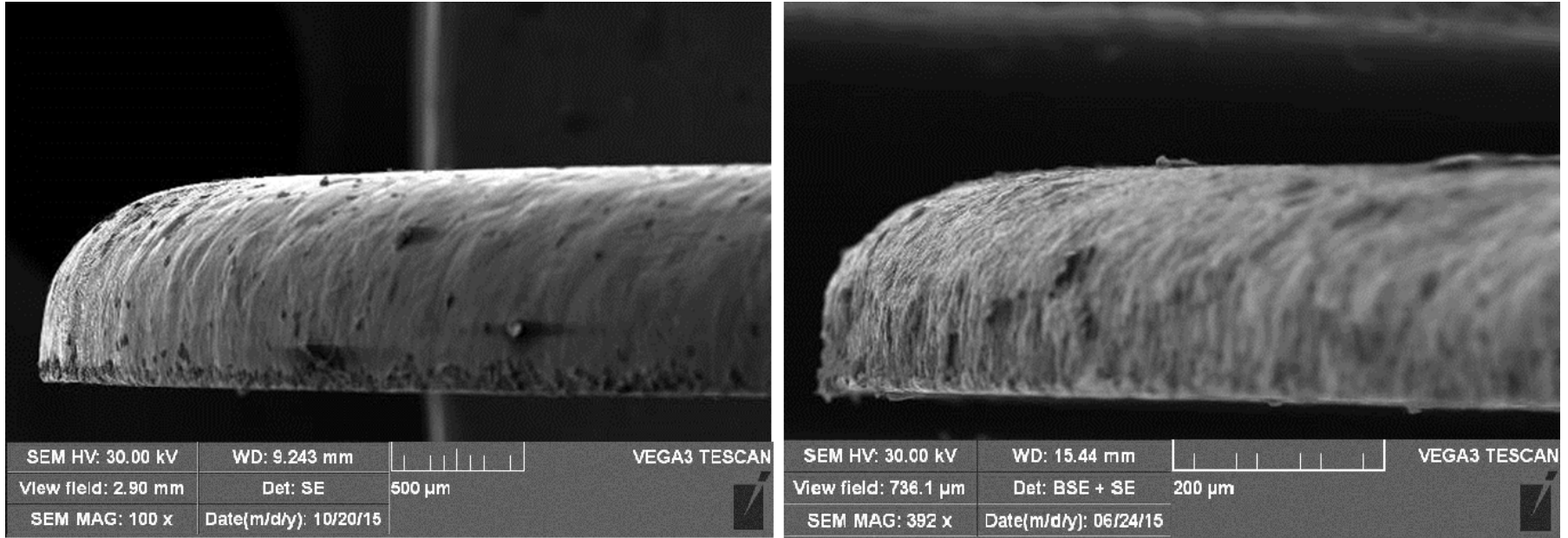

Fig. 11. Surface of blank 
from the test results:

- $\quad$ electromagnetic cutting can be done using conventional tools supplemented with a working head,

- $\quad$ in the case of the first method the cutting process would proceed correctly for the spacer washer thickness of $2.1 \mathrm{~mm}$;

- $\quad$ for the second method the optimum experimentally determined tool length needed to cut through the material was $5.5 \mathrm{~mm}$;

- holes could be punching in the two tested materials when an energy of $1.20 \mathrm{~kJ}$ was applied and when the energy was increased to $1.57 \mathrm{~kJ}$, the quality of the obtained product improved;

- owing to the high quality of the obtained surfaces of the cut, the cutting process does not entail additional costs of removing burrs.

- the shape of the cut is different than the one obtained by traditional blanking - no zones characteristic of the latter are present here.

- the rollover of the sheet metal surface, observed in the initial elastoplastic stage of cutting, is much larger than in the case of the conventional method.

As compared with the conventional method, the electromagnetic machining technology ensures a high quality surface of the cut at reduced electricity consumption in the industry.

\section{REFERENCES}

[1] M. Kamal, G.S. Daehn, Journal of Manufacturing Science and Engineering 129 (2), 369-379 (2007).

[2] M. Kamal, J. Shang, V. Cheng, S. Hatkevich, G.S. Daehn, Journal of Materials Processing Technology 190 (1), 41-50 (2007).
[3] H. Friedrich, Automobil-technische Zeitschrift-ATZ 104 (3), 258266 (2002).

[4] V. Psyka, D. Rischa, B.L. Kinseyb, A.E. Tekkayaa, M. Kleinera, Journal of Materials Processing Technology 211, 787-829 (2011).

[5] Z. Zimniak, G. Radkiewicz, Production Engineering Innovations and Technologies of the Future, Wroclaw (2011).

[6] D.F. Brower, Metals Handbook, Metals Park. 4 ASM, Ohio (1969).

[7] S. Golowin, PhD thesis, The Ohio State University, (2008).

[8] T. Kautz, Dr.-Ing. Dissertation, Otto-von-Guericke-Universität Magdeburg, (2008).

[9] R. Hahn, Dr.-Ing. Dissertation, Technische Universität, Berlin (2004).

[10] R. Neugebauer, F. Löschmann, M. Putz, T. Koch, G. Laux, ICHSF 06, Dortmund (2006).

[11] R. Schäfer, P. Pasquale, Umformtechnischen Kolloquium Darmstadt, Verlag Meisenbach Bamberg (2009).

[12] T. Kautz, Shaker-Verlag, Aachen (2008).

[13] P. Maier-Komor, Impulsmagnetisches Colloquium, Dortmund (2009).

[14] P. Kumar, A. Mishra, T. Watt, I. Dutta, D.L. Bourell, U. Sahaym, Procedia CIRP 6, 600-604 (2013).

[15] S. Satapathy, F. Stefani, A. Saenz, IEEE Trans. On Magnetics 41, 226-230 (2005).

[16] G. Yagawa, T. Horie, Nuclear Eng. and Design 69, 49-52 (1982).

[17] V.M. Finket, Y.I. Golovin, A.A. Sletkov, Sov. Phys. Dokl. 22, 11-17 (1977).

[18] T.E. James, IEEE Trans. Magnetics 31, 622-627 (1995).

[19] R. Schäfer, P. Pasquale, Whitepaper PST products GmbH (2009).

[20] V. Kräusel, R. Schäfer, L. Engelbrecht, Gepulste elektromagnetische Felder schneiden hochfeste Bleche Maschinenmarkt 4, 26-29 (2010). 